\title{
Nucleofugality of Aliphatic Carboxylates in Mixtures of Aprotic Solvents and Water ${ }^{\dagger}$
}

\author{
Mirela Matić, Bernard Denegri, ${ }^{*}$ and Olga Kronja* \\ University of Zagreb, Faculty of Pharmacy and Biochemistry, Ante Kovačića 1, HR-10000 Zagreb, Croatia
}

RECEIVED JUNE 18, 2014; REVISED JULY 16, 2014; ACCEPTED JULY 28, 2014

\begin{abstract}
The leaving group ability (nucleofugality) of fluoroacetate, chloroacetate, bromoacetate, dichloroacetate, trifluoroacetate, trichloroacetate, heptafluorobutyrate, formate, isobutyrate, and pivalate have been derived from the solvolysis rate constants of the corresponding X,Y-substituted benzhydryl carboxylates in $60 \%$ and $80 \%$ aqueous acetonitrile and $60 \%$ aqueous acetone, applying the LFER equation: log $k=s_{\mathrm{f}}\left(E_{\mathrm{f}}+N_{\mathrm{f}}\right)$. The experimental barriers $\left(\Delta G^{\ddagger \text { exp }}\right)$ for solvolyses of 11 reference dianisylmethyl carboxylates in these solvents correlate very well ( $r=0.994$ in all solvents) with $\Delta G^{\ddagger \text {,model }}$ of the model $\sigma$-assisted heterolytic displacement reaction of cis-2,3-dihydroxycyclopropyl trans-carboxylates calculated earlier. Linear correlation observed between the $\log k$ for the reference dianisylmethyl carboxylates and the $s$ f values enables estimation of the reaction constant $\left(s_{\mathrm{f}}^{\text {estim }}\right)$. Using the $\Delta G^{\ddagger \text {,exp }}$ vs. $\Delta G^{\ddagger \text {,model }}$ correlation, and taking the estimated $s_{\mathrm{f}}^{\text {estim }}$, the nucleofugality parameters for other 34 aliphatic carboxylates have been determined in $60 \%$ and $80 \%$ aqueous acetonitrile and $60 \%$ aqueous acetone. The most important variable that determines the reactivity of aliphatic carboxylates in aprotic solvent/water mixtures is the inductive effect of the group(s) attached onto the carboxylate moiety.
\end{abstract}

Keywords: nucleofugality, reactivity, aliphatic carboxylates, benzhydryl, hydrolysis, solvolysis, model reaction, correlation

\section{INTRODUCTION}

Carboxylate esters constitute a large group of organic products and intermediates, as well as substrates for investigation the reaction mechanisms. They react with solvents via $\mathrm{S}_{\mathrm{N}} 1$ route if a stabilized carbocation intermediate is produced after the departure of the carboxylate leaving group..$^{1,2,3}$ Therefore, to handle carboxylates properly in organic syntheses, it is important to be able to estimate their solvolytic reactivity.

The rate of the heterolytic step in $\mathrm{S}_{\mathrm{N}} 1$ solvolysis depends on the ability of a leaving group to depart from a substrate in a given solvent (nucleofugality) as well as on the ability of a carbocation moiety to leave a molecule (electrofugality). ${ }^{4,5}$ These parameters have been related in the following special LFER equation developed on solvolysis of benzhydryl derivatives:

$$
\log k\left(25^{\circ} \mathrm{C}\right)=s_{\mathrm{f}}\left(E_{\mathrm{f}}+N_{\mathrm{f}}\right)
$$

in which: $k$ is the first-order rate constant for $\mathrm{S}_{\mathrm{N}} 1$ reaction, $s_{\mathrm{f}}$ (slope of the $\log k \mathrm{vs}$. $E_{\mathrm{f}}$ linear plot) and $N_{\mathrm{f}}$ (negative intercept on the abscissa) are the nucleofugespecific parameters, and $E_{\mathrm{f}}$ is the electrofugality para- meter. $^{5}$ Thus, the reactivity of a given nucleofuge in a given solvent is defined by two variables, the slope parameter $\left(s_{\mathrm{f}}\right)$ and the nucleofugality $\left(N_{\mathrm{f}}\right)$, whose product $\left(s_{\mathrm{f}} \times N_{\mathrm{f}}\right)$ corresponds to $\log k$ for solvolysis of its dianisylmethyl derivative at $25{ }^{\circ} \mathrm{C}$, since $E_{\mathrm{f}}=0$ for dianisylmethyl electrofuge. To determine the nucleofuge-specific parameters by Equation 1, the logarithms of the first-order rate constants are plotted against the corresponding $E_{\mathrm{f}}$ values of the reference benzhydrylium ions defined earlier. ${ }^{5}$ Availability of $N_{\mathrm{f}}$ and $s_{\mathrm{f}}$ parameters enables estimation of the solvolytic reactivity of any substrate semiquantitatively, as well as comparison of the reactivity of a given carboxylate with reactivities of other leaving groups in a given solvent.

We have recently investigated the solvolytic reactivity of numerous aliphatic carboxylates in ethanolic solvents determining their leaving group ability (nucleofugality).,3 Eleven different X,Y-substituted benzhydryl carboxylates have been subjected to solvolytic measurements, and from the linear correlation between first-order solvolysis rates $(\log k)$ and the electrofugality parameters of the corresponding benzhydrylium ions $\left(E_{\mathrm{f}}\right)$, their nucleofuge-specific parameters were calculated (Equation 1). It has been

\footnotetext{
$\dagger$ Dedicated to Dr. Mirjana Eckert-Maksić on the occasion of her $70^{\text {th }}$ birthday.

* Authors to whom correspondence should be addressed. (E-mail: bdenegri@pharma.hr; okronja@pharma.hr)
} 
shown that the most important variable that determines their order of reactivity is the inductive effect of the substituents attached onto the carboxyl group. ${ }^{3}$

The transition state of heterolysis of a neutral substrate that produces a positively charged electrofuge (here benzhydrylium ion) and a negatively charged nucleofuge (here carboxylate ion) cannot be optimized by quantum chemical calculations. Therefore, we presented earlier a method for predicting the nucleofugality of any aliphatic carboxylate leaving group in aqueous ethanol mixtures using the computed model reaction in which the heterolysis is accompanied with a neighboring group assistance. ${ }^{6}$ The disrotatory cyclopropyl ring opening in cis-2,3-dihydroxycyclopropyl trans-carboxylates that is concerted with the departure of the carboxylate leaving group (backside $\sigma$-participation) has been used for the model reaction (Scheme 1). The ground state structures and the corresponding transition state structures of eleven 2,3-dihydroxycyclopropyl carboxylates shown in Scheme 1 have been optimized at the M06-2X/AUG-cc-pVTZ level of theory ${ }^{7}$ in the presence of the IEFPCM solvation model $^{8}$ that mimics a solvent, and the Gibbs free energies of activation $\left(\Delta G^{\ddagger \text {,model }}\right)$ for the model reaction have been calculated. The correlation between experimental barriers $\left(\Delta G^{\ddagger}, \exp \right)$ for solvolysis of the 11 reference dianisylmethyl carboxylates in the series of aqueous ethanol mixtures and the heterolytic barriers of the model reaction obtained by quantum chemical calculations produce a very good linear fit, with the slope close to unity and the correlation coefficient of $0.994-0.997 .{ }^{6}$ Accordingly, to predict the reactivity of a particular carboxylate in an ethanolic solvent, the barrier of the model reaction for a given leaving group should be determined computationally. From the correlation line between experimental $\Delta G^{\dagger}$,exp vs. calculated $\Delta G^{\ddagger}$,model for the model reaction, the reactivity of dianisylmethyl derivative of any carboxylate studied can be determined.

In this work we have focused our attention to investigate the solvolytic behavior of aliphatic carboxylates in mixtures of aprotic solvents and water, particularly to aqueous acetone and acetonitrile. In these commonly used solvent mixtures only water acts as a nucleophile, i.e., hydrolysis occurs. We set out to determine the nucleofugalities of carboxylates (fluoroacetate, chloro-acetate,

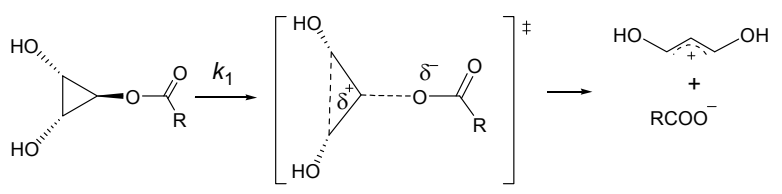

$\mathrm{R}=\mathrm{FCH}_{2}$ (fluoroacetate), $\mathrm{ClCH}_{2}$ (chloroacetate), $\mathrm{BrCH}_{2}$ (bromoacetate), $\mathrm{Cl}_{2} \mathrm{CH}$ (dichloroacetate), $\mathrm{CF}_{3}$ (trifluoroacetate), $\mathrm{CCl}_{3}$ (trichloroacetate), $\mathrm{C}_{3} \mathrm{~F}_{7}$ (heptafluorobutyrate), $\mathrm{H}$ (formate), $\mathrm{CH}_{3}$ (acetate), $\left(\mathrm{CH}_{3}\right)_{2} \mathrm{CH}$ (isobutyrate), $\left(\mathrm{CH}_{3}\right)_{3} \mathrm{C}$ (pivalate)

Scheme 1. Model reaction. bromoacetate, dichloroacetate, trifluoroacetate, trichloroacetate, heptafluorobutyrate, formate, isobut-yrate, pivalate) experimentally, and to use those experimental data as reference values for the correlation with the computed barriers of the model reaction determined earlier. ${ }^{6}$ Using the theoretical model mentioned above, we have tested and justified the applicability of the method for predicting heterolysis rate in the mixtures of aprotic solvents and water, and also determined nucleofugalities of numerous other aliphatic carboxylates.

\section{EXPERIMENTAL SECTION}

\section{Substrate Preparation:}

All substrates were prepared according to the procedure described in References 2 and 3.

\section{Kinetic Methods}

Hydrolysis rate constants were measured conductometrically. Freshly prepared solvents $(30 \mathrm{~mL})$ were thermostated $\left( \pm 0.1{ }^{\circ} \mathrm{C}\right)$ at a given temperature for several minutes prior to addition of the substrate. Typically, $10-30 \mathrm{mg}$ of substrate were dissolved in $0.10-0.15 \mathrm{~mL}$ of dichloromethane and injected into solvent. The increase of the conductivity during hydrolysis was monitored automatically by means of a WTW LF 530 conductometer using the Radiometer 2-pole Conductivity Cell (CDC641T). Individual rate constants were obtained by least-squares fitting of the conductivity data to the first-order kinetic equation for 3-4 half lives. The rate constants were averaged from at least three measurements. In order to achieve a complete ionization of a liberated acid, either a proton sponge base [1,8bis(dimethylamino) naphthalene] or lutidine was added. The typical molar ratio between the base and a substrate ranged from 1.5 to 15.0 for proton sponge, and from 2.0 to 17.0 for lutidine, depending on a combination of acidity of a liberated carboxylic acid and an employed solvent. A calibration showed a linear response of conductivity in the presented ranges of concentrations of the bases and carboxylic acids liberated in examined hydrolyses.

\section{RESULTS AND DISCUSSION}

\section{Solvolysis in Aprotic Solvent/Water Mixtures}

The first-order solvolysis rates of X,Y-substituted benzhydryl carboxylates (1, Scheme 2) have been measured conductometrically in $60 \%$ aqueous acetone, and $80 \%$ and $60 \%$ aqueous acetonitrile at $25{ }^{\circ} \mathrm{C}$ or at least three different temperatures and extrapolated to $25{ }^{\circ} \mathrm{C}$. Details are given in Kinetic Methods (Experimental Section). The first-order rate constants are presented in Table 1. 
Table 1. Solvolysis rate constants of different X,Y-substituted benzhydryl carboxylates in various solvents at $25^{\circ} \mathrm{C}$

\begin{tabular}{|c|c|c|c|c|}
\hline Carboxylate & $(\mathrm{X}, \mathrm{Y})$ & $E_{\mathrm{f}}$ (a) & Solvent ${ }^{(b)}$ & $k / \mathrm{s}^{-1(\mathrm{c})}$ \\
\hline \multirow[t]{12}{*}{ Fluoroacetate } & 4-MeO, $\mathrm{H}$ & -2.09 & $60 \mathrm{~A} 40 \mathrm{~W}$ & $(6.19 \pm 0.09) \times 10^{-5}$ \\
\hline & 4-MeO, 4-Me & -1.32 & & $(3.35 \pm 0.05) \times 10^{-4}$ \\
\hline & 4-MeO, 4- $\mathrm{PhO}$ & -0.86 & & $(6.85 \pm 0.04) \times 10^{-4}$ \\
\hline & 4-MeO, 4-MeO & 0.00 & & $(6.09 \pm 0.08) \times 10^{-3}$ \\
\hline & 4-MeO, $\mathrm{H}$ & -2.09 & 80AN20W & $1.83 \times 10^{-5(\mathrm{~d})}$ \\
\hline & 4-MeO, 4-Me & -1.32 & & $(1.01 \pm 0.02) \times 10^{-4}$ \\
\hline & 4-MeO, 4- $\mathrm{PhO}$ & -0.86 & & $(2.62 \pm 0.02) \times 10^{-4}$ \\
\hline & 4-MeO, 4-MeO & 0.00 & & $(2.04 \pm 0.05) \times 10^{-3}$ \\
\hline & 4-MeO, $\mathrm{H}$ & -2.09 & 60AN40W & $(8.80 \pm 0.09) \times 10^{-5}$ \\
\hline & 4-MeO, 4-Me & -1.32 & & $(4.56 \pm 0.05) \times 10^{-4}$ \\
\hline & 4-MeO, 4- $\mathrm{PhO}$ & -0.86 & & $(9.46 \pm 0.10) \times 10^{-4}$ \\
\hline & 4-MeO, 4-MeO & 0.00 & & $(7.20 \pm 0.10) \times 10^{-3}$ \\
\hline \multirow[t]{12}{*}{ Chloroacetate } & 4-MeO, $\mathrm{H}$ & -2.09 & $60 \mathrm{~A} 40 \mathrm{~W}$ & $(3.13 \pm 0.06) \times 10^{-5}$ \\
\hline & 4-MeO, 4-Me & -1.32 & & $(1.68 \pm 0.03) \times 10^{-4}$ \\
\hline & 4-MeO, 4-PhO & -0.86 & & $(3.72 \pm 0.05) \times 10^{-4}$ \\
\hline & 4-MeO, 4-MeO & 0.00 & & $(3.48 \pm 0.03) \times 10^{-3}$ \\
\hline & 4-MeO, $\mathrm{H}$ & -2.09 & 80AN20W & $9.93 \times 10^{-6(d)}$ \\
\hline & 4-MeO, 4-Me & -1.32 & & $(6.06 \pm 0.08) \times 10^{-5}$ \\
\hline & 4-MeO, 4-PhO & -0.86 & & $(1.64 \pm 0.02) \times 10^{-4}$ \\
\hline & 4-MeO, 4-MeO & 0.00 & & $(1.32 \pm 0.02) \times 10^{-3}$ \\
\hline & 4-MeO, $\mathrm{H}$ & -2.09 & 60AN40W & $(4.63 \pm 0.05) \times 10^{-5}$ \\
\hline & 4-MeO, 4-Me & -1.32 & & $(2.44 \pm 0.04) \times 10^{-4}$ \\
\hline & 4-MeO, 4-PhO & -0.86 & & $(5.37 \pm 0.08) \times 10^{-4}$ \\
\hline & 4-MeO, 4-MeO & 0.00 & & $(4.30 \pm 0.08) \times 10^{-3}$ \\
\hline \multirow[t]{12}{*}{ Bromoacetate } & 4-MeO, $\mathrm{H}$ & -2.09 & $60 \mathrm{~A} 40 \mathrm{~W}$ & $(3.03 \pm 0.10) \times 10^{-5}$ \\
\hline & 4-MeO, 4-Me & -1.32 & & $(1.64 \pm 0.02) \times 10^{-4}$ \\
\hline & 4-MeO, 4-PhO & -0.86 & & $(3.60 \pm 0.08) \times 10^{-4}$ \\
\hline & 4-MeO, 4-MeO & 0.00 & & $(3.36 \pm 0.05) \times 10^{-3}$ \\
\hline & 4-MeO, $\mathrm{H}$ & -2.09 & 80AN20W & $1.02 \times 10^{-5(\mathrm{~d})}$ \\
\hline & 4-MeO, 4-Me & -1.32 & & $(5.87 \pm 0.05) \times 10^{-5}$ \\
\hline & 4-MeO, 4-PhO & -0.86 & & $(1.58 \pm 0.02) \times 10^{-4}$ \\
\hline & 4-MeO, 4-MeO & 0.00 & & $(1.26 \pm 0.02) \times 10^{-3}$ \\
\hline & 4-MeO, $\mathrm{H}$ & -2.09 & 60AN40W & $(4.57 \pm 0.08) \times 10^{-5}$ \\
\hline & 4-MeO, 4-Me & -1.32 & & $(2.35 \pm 0.04) \times 10^{-4}$ \\
\hline & 4-MeO, 4-PhO & -0.86 & & $(5.11 \pm 0.08) \times 10^{-4}$ \\
\hline & 4-MeO, 4-MeO & 0.00 & & $(4.20 \pm 0.05) \times 10^{-3}$ \\
\hline \multirow[t]{10}{*}{ Dichloroacetate } & 4-Me, 4-Me & -3.44 & $60 \mathrm{~A} 40 \mathrm{~W}$ & $(1.17 \pm 0.01) \times 10^{-4}$ \\
\hline & 4-MeO, $\mathrm{H}$ & -2.09 & & $(1.77 \pm 0.02) \times 10^{-3}$ \\
\hline & 4-MeO, 4-Me & -1.32 & & $(8.76 \pm 0.06) \times 10^{-3}$ \\
\hline & 4-MeO, 4- $\mathrm{PhO}$ & -0.86 & & $(1.98 \pm 0.01) \times 10^{-2}$ \\
\hline & 4-Me, $\mathrm{H}$ & -4.63 & 80AN20W & $4.43 \times 10^{-6}(\mathrm{~d})$ \\
\hline & 4-Me, 4-Me & -3.44 & & $(5.85 \pm 0.08) \times 10^{-5}$ \\
\hline & 4-MeO, $\mathrm{H}$ & -2.09 & & $(9.19 \pm 0.02) \times 10^{-4}$ \\
\hline & 4-MeO, 4-Me & -1.32 & & $(5.06 \pm 0.02) \times 10^{-3}$ \\
\hline & 4-Me, $\mathrm{H}$ & -4.63 & 60AN40W & $2.24 \times 10^{-5}(\mathrm{~d})$ \\
\hline & 4-Me, 4-Me & -3.44 & & $(2.37 \pm 0.02) \times 10^{-4}$ \\
\hline
\end{tabular}


Table 1. Solvolysis rate constants of different $\mathrm{X}, \mathrm{Y}$-substituted benzhydryl carboxylates in various solvents at $25^{\circ} \mathrm{C}$

\begin{tabular}{|c|c|c|c|c|}
\hline Carboxylate & $(\mathrm{X}, \mathrm{Y})$ & $E_{\mathrm{f}}(\mathrm{a})$ & Solvent ${ }^{(b)}$ & $k / \mathrm{s}^{-1}(\mathrm{c})$ \\
\hline \multirow[t]{2}{*}{ Dichloroacetate } & 4-MeO, $\mathrm{H}$ & -2.09 & 60AN40W & $(2.95 \pm 0.02) \times 10^{-3}$ \\
\hline & 4-MeO, 4-Me & -1.32 & & $(1.47 \pm 0.02) \times 10^{-2}$ \\
\hline \multirow[t]{8}{*}{ Trifluoroacetate } & $\mathrm{H}, \mathrm{H}$ & -6.03 & $80 \mathrm{AN} 20 \mathrm{~W}$ & $(7.84 \pm 0.06) \times 10^{-5}$ \\
\hline & 4-F, H & -5.72 & & $(1.51 \pm 0.02) \times 10^{-4}$ \\
\hline & 4-Me, $\mathrm{H}$ & -4.63 & & $(1.43 \pm 0.02) \times 10^{-3}$ \\
\hline & 4-Me, 4-Me & -3.44 & & $(1.73 \pm 0.01) \times 10^{-2}$ \\
\hline & $\mathrm{H}, \mathrm{H}$ & -6.03 & $60 \mathrm{AN} 40 \mathrm{~W}$ & $(2.74 \pm 0.01) \times 10^{-4}$ \\
\hline & 4-F, H & -5.72 & & $(5.15 \pm 0.07) \times 10^{-4}$ \\
\hline & 4-Me, $\mathrm{H}$ & -4.63 & & $(4.46 \pm 0.02) \times 10^{-3}$ \\
\hline & 4-Me, 4-Me & -3.44 & & $(4.64 \pm 0.05) \times 10^{-2}$ \\
\hline \multirow[t]{12}{*}{ Trichloroacetate } & $\mathrm{H}, \mathrm{H}$ & -6.03 & $60 \mathrm{~A} 40 \mathrm{~W}$ & $(5.52 \pm 0.01) \times 10^{-5}$ \\
\hline & 4-F, H & -5.72 & & $(1.04 \pm 0.01) \times 10^{-4}$ \\
\hline & 4-Me, $\mathrm{H}$ & -4.63 & & $(8.47 \pm 0.02) \times 10^{-4}$ \\
\hline & 4-Me, 4-Me & -3.44 & & $(9.65 \pm 0.00) \times 10^{-3}$ \\
\hline & $\mathrm{H}, \mathrm{H}$ & -6.03 & $80 \mathrm{AN} 20 \mathrm{~W}$ & $(5.00 \pm 0.08) \times 10^{-5}$ \\
\hline & 4-F, H & -5.72 & & $(7.65 \pm 0.01) \times 10^{-5}$ \\
\hline & 4-Me, $\mathrm{H}$ & -4.63 & & $(6.29 \pm 0.06) \times 10^{-4}$ \\
\hline & 4-Me, 4-Me & -3.44 & & $(7.09 \pm 0.02) \times 10^{-3}$ \\
\hline & $\mathrm{H}, \mathrm{H}$ & -6.03 & $60 \mathrm{AN} 40 \mathrm{~W}$ & $(9.21 \pm 0.01) \times 10^{-5}$ \\
\hline & 4-F, H & -5.72 & & $(1.74 \pm 0.00) \times 10^{-4}$ \\
\hline & 4-Me, $\mathrm{H}$ & -4.63 & & $(1.69 \pm 0.03) \times 10^{-3}$ \\
\hline & 4-Me, 4-Me & -3.44 & & $(1.84 \pm 0.01) \times 10^{-2}$ \\
\hline \multirow[t]{8}{*}{ Heptafluorobutyrate } & 4-Cl, H & -6.44 & 80AN20W & $(5.22 \pm 0.02) \times 10^{-5}$ \\
\hline & $\mathrm{H}, \mathrm{H}$ & -6.03 & & $(1.10 \pm 0.00) \times 10^{-4}$ \\
\hline & 4-F, H & -5.72 & & $(2.23 \pm 0.00) \times 10^{-4}$ \\
\hline & 4-Me, $\mathrm{H}$ & -4.63 & & $(2.49 \pm 0.00) \times 10^{-3}$ \\
\hline & 4-Cl, H & -6.44 & $60 \mathrm{AN} 40 \mathrm{~W}$ & $(1.66 \pm 0.00) \times 10^{-4}$ \\
\hline & $\mathrm{H}, \mathrm{H}$ & -6.03 & & $(3.50 \pm 0.00) \times 10^{-4}$ \\
\hline & 4-F, H & -5.72 & & $(7.01 \pm 0.05) \times 10^{-4}$ \\
\hline & 4-Me, $\mathrm{H}$ & -4.63 & & $(6.53 \pm 0.03) \times 10^{-3}$ \\
\hline \multirow[t]{12}{*}{ Formate } & 4-MeO, $\mathrm{H}$ & -2.09 & $60 \mathrm{~A} 40 \mathrm{~W}$ & $(2.11 \pm 0.02) \times 10^{-5}$ \\
\hline & 4-MeO, 4-Me & -1.32 & & $(1.23 \pm 0.01) \times 10^{-4}$ \\
\hline & 4-MeO, 4-PhO & -0.86 & & $(2.63 \pm 0.10) \times 10^{-4}$ \\
\hline & 4-MeO, 4-MeO & 0.00 & & $(2.46 \pm 0.04) \times 10^{-3}$ \\
\hline & 4-MeO, $\mathrm{H}$ & -2.09 & $80 \mathrm{AN} 20 \mathrm{~W}$ & $6.61 \times 10^{-6(d)}$ \\
\hline & 4-MeO, 4-Me & -1.32 & & $(3.67 \pm 0.04) \times 10^{-5}$ \\
\hline & 4-MeO, 4-PhO & -0.86 & & $(9.36 \pm 0.09) \times 10^{-5}$ \\
\hline & 4-MeO, 4-MeO & 0.00 & & $(7.96 \pm 0.04) \times 10^{-4}$ \\
\hline & 4-MeO, $\mathrm{H}$ & -2.09 & $60 \mathrm{AN} 40 \mathrm{~W}$ & $(3.81 \pm 0.06) \times 10^{-5}$ \\
\hline & 4-MeO, 4-Me & -1.32 & & $(2.09 \pm 0.02) \times 10^{-4}$ \\
\hline & 4-MeO, 4- $\mathrm{PhO}$ & -0.86 & & $(4.29 \pm 0.05) \times 10^{-4}$ \\
\hline & 4-MeO, 4-MeO & 0.00 & & $(3.57 \pm 0.04) \times 10^{-3}$ \\
\hline \multirow[t]{3}{*}{ Isobutyrate } & 4-MeO, 4-MeO & 0.00 & $60 \mathrm{~A} 40 \mathrm{~W}$ & $6.56 \times 10^{-6(d)}$ \\
\hline & 4-MeO, 4-MeO & 0.00 & 80AN20W & $2.82 \times 10^{-6(\mathrm{~d})}$ \\
\hline & 4-MeO, 4-MeO & 0.00 & $60 \mathrm{AN} 40 \mathrm{~W}$ & $1.08 \times 10^{-5(\mathrm{~d})}$ \\
\hline Pivalate & 4-MeO, 4-MeO & 0.00 & $60 \mathrm{AN} 40 \mathrm{~W}$ & $3.72 \times 10^{-6}$ (d) \\
\hline
\end{tabular}

(a) Electrofugality parameters are taken from Reference 5.

(b) Binary solvents are expressed as volume fractions at $25^{\circ} \mathrm{C}$ : $\mathrm{A}=$ acetone, $\mathrm{AN}=$ acetonitrile, $\mathrm{W}=$ water.

(c) Average rate constants from at least three runs performed at $25^{\circ} \mathrm{C}$ unless otherwise noted. Errors shown are standard deviations.

${ }^{(d)}$ Extrapolated from data at higher temperatures using the Eyring equation. 


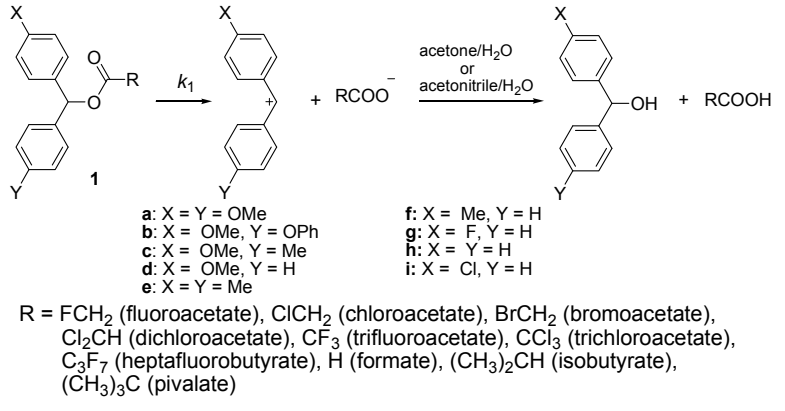

Scheme 2. Solvolysis of X,Y-substituted benzhydryl carboxylates.

In order to calculate the nucleofugality $\left(N_{\mathrm{f}}\right)$ and slope $\left(s_{\mathrm{f}}\right)$ parameters for the carboxylates indicated in Scheme 2, the logarithms of the first-order rate constants were plotted against reference electrofugalities determined earlier. ${ }^{5}$ The plots of $\log k$ against $E_{\mathrm{f}}$ are given in Figure 1, whereas the extracted nucleofugespecific parameters are given in Table 2 .

Since isobutyrate and pivalate represent poor leaving groups, we were able to measure the rate constants only for their dianisylmethyl derivatives by conventional methods. To determine the nucleofuge-specific parameters for these leaving groups from a single kinetic datum, the value of $s_{\mathrm{f}}$ parameter should first be estimated. It has been observed for carboxylates investigated here that in ethanolic solvents the $s_{\mathrm{f}}$ parameter decreases linearly as the reactivity of a substrate increases ( $r=$ 0.94 in $80 \%$ aq. ethanol). ${ }^{3}$ Such an observation has been rationalized that less reactive substrates solvolyze via more carbocation-like transition state, which is in accord with the Hammond postulate.

We have examined how the value of the slope parameter $s_{\mathrm{f}}$ depends on the reaction rate in the solvent mixtures used here. Therefore, we plotted the logarithms of rate constants of dianisylmethyl carboxylates

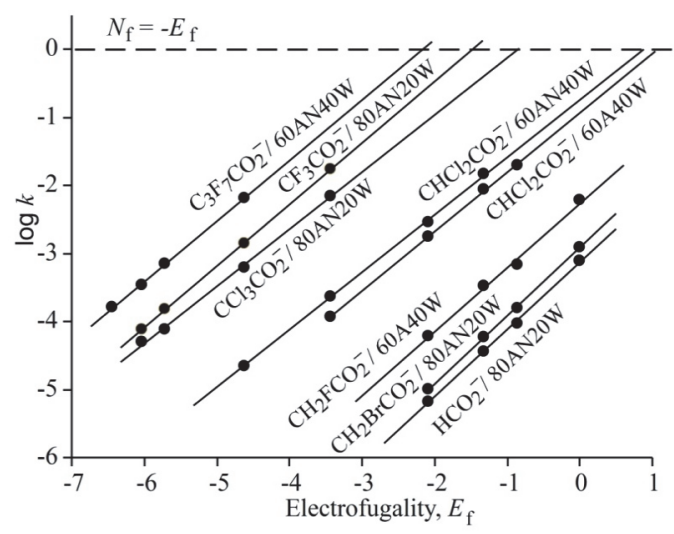

Figure 1. Plots of $\log k\left(25^{\circ} \mathrm{C}\right)$ versus $E_{\mathrm{f}}$ for hydrolysis of substituted benzhydryl carboxylates in aqueous acetonitrile (AN) and aqueous acetone (A) mixtures.
Table 2. Nucleofugality parameters $N_{\mathrm{f}}$ and $s_{\mathrm{f}}$ for different carboxylates in various solvents

\begin{tabular}{|c|c|c|c|}
\hline Leaving group & Solvent ${ }^{\text {(a) }}$ & $N_{\mathrm{f}}{ }^{(\mathrm{b})}$ & $S \mathrm{f}^{(\mathrm{b})}$ \\
\hline \multirow[t]{3}{*}{ Fluoroacetate } & $60 \mathrm{~A} 40 \mathrm{~W}$ & $-2.40 \pm 0.19$ & $0.94 \pm 0.05$ \\
\hline & 80AN20W & $-2.77 \pm 0.07$ & $0.98 \pm 0.02$ \\
\hline & 60AN40W & $-2.38 \pm 0.15$ & $0.91 \pm 0.04$ \\
\hline \multirow[t]{3}{*}{ Chloroacetate } & $60 \mathrm{~A} 40 \mathrm{~W}$ & $-2.59 \pm 0.19$ & $0.97 \pm 0.05$ \\
\hline & 80AN20W & $-2.86 \pm 0.06$ & $1.01 \pm 0.02$ \\
\hline & 60AN40W & $-2.58 \pm 0.15$ & $0.93 \pm 0.04$ \\
\hline \multirow[t]{3}{*}{ Bromoacetate } & $60 \mathrm{~A} 40 \mathrm{~W}$ & $-2.60 \pm 0.19$ & $0.97 \pm 0.05$ \\
\hline & $80 \mathrm{AN} 20 \mathrm{~W}$ & $-2.92 \pm 0.06$ & $1.00 \pm 0.02$ \\
\hline & $60 \mathrm{AN} 40 \mathrm{~W}$ & $-2.60 \pm 0.16$ & $0.93 \pm 0.04$ \\
\hline \multirow[t]{3}{*}{ Dichloroacetate } & $60 \mathrm{~A} 40 \mathrm{~W}$ & $-1.07 \pm 0.04$ & $0.87 \pm 0.01$ \\
\hline & $80 \mathrm{AN} 20 \mathrm{~W}$ & $-1.18 \pm 0.04$ & $0.92 \pm 0.01$ \\
\hline & 60AN40W & $-0.87 \pm 0.05$ & $0.85 \pm 0.01$ \\
\hline \multirow{2}{*}{ Trifluoroacetate } & $80 \mathrm{AN} 20 \mathrm{~W}$ & $1.49 \pm 0.01$ & $0.90 \pm 0.01$ \\
\hline & $60 \mathrm{AN} 40 \mathrm{~W}$ & $1.90 \pm 0.01$ & $0.86 \pm 0.01$ \\
\hline \multirow[t]{3}{*}{ Trichloroacetate } & $60 \mathrm{~A} 40 \mathrm{~W}$ & $1.09 \pm 0.04$ & $0.86 \pm 0.01$ \\
\hline & $80 \mathrm{AN} 20 \mathrm{~W}$ & $0.86 \pm 0.12$ & $0.84 \pm 0.02$ \\
\hline & $60 \mathrm{AN} 40 \mathrm{~W}$ & $1.49 \pm 0.02$ & $0.89 \pm 0.01$ \\
\hline \multirow[t]{2}{*}{ Heptafluorobutyrate } & $80 \mathrm{AN} 20 \mathrm{~W}$ & $1.84 \pm 0.10$ & $0.94 \pm 0.02$ \\
\hline & $60 \mathrm{AN} 40 \mathrm{~W}$ & $2.16 \pm 0.06$ & $0.89 \pm 0.02$ \\
\hline \multirow[t]{3}{*}{ Formate } & $60 \mathrm{~A} 40 \mathrm{~W}$ & $-2.70 \pm 0.19$ & $0.98 \pm 0.05$ \\
\hline & 80AN20W & $-3.16 \pm 0.12$ & $0.99 \pm 0.03$ \\
\hline & $60 \mathrm{AN} 40 \mathrm{~W}$ & $-2.67 \pm 0.19$ & $0.93 \pm 0.05$ \\
\hline \multirow[t]{3}{*}{ Isobutyrate ${ }^{(c)}$} & $60 \mathrm{~A} 40 \mathrm{~W}$ & -4.71 & 1.10 \\
\hline & 80AN20W & -5.14 & 1.08 \\
\hline & $60 \mathrm{AN} 40 \mathrm{~W}$ & -4.92 & 1.01 \\
\hline Pivalate $^{(\mathrm{c})}$ & $60 \mathrm{AN} 40 \mathrm{~W}$ & -5.32 & 1.02 \\
\hline
\end{tabular}

(a) Binary solvents are expressed as volume fractions at $25^{\circ} \mathrm{C}$ : $\mathrm{AN}=$ acetonitrile, $\mathrm{A}=$ acetone, $\mathrm{W}=$ water.

(b) Errors shown are standard errors.

(c) $s \mathrm{f}$ values were estimated from the $s \mathrm{f} / \log k$ correlations of dianisylmethyl carboxylates.

$\left(1, \mathrm{X}=\mathrm{Y}=\mathrm{OCH}_{3}\right)$ against the corresponding $s_{\mathrm{f}}$ parameters for each solvent separately. The rate constants of dianisylmethyl carboxylates used for correlation are those determined here, as well as those presented in Reference 5 (nine data points for each solvent; correlation plots and tabular presentation of the data are given in the Supporting Information). The decreasing trend of $s_{\mathrm{f}}$ values with increasing reactivity of carboxylates has been observed in all solvents used (the correlation line obtained in $60 \%$ aq. acetone is shown in Figure 2. Correlations for $60 \%$ and $80 \%$ aq. acetonitrile are presented in the Supporting Information.).

Even though the individual $s_{\mathrm{f}}$ values somewhat deviate from the correlation plots $(r=0.88$ in $60 \%$ aq. acetone; $r=0.86$ in $80 \%$ aq. acetonitrile; $r=0.77$ in 60 


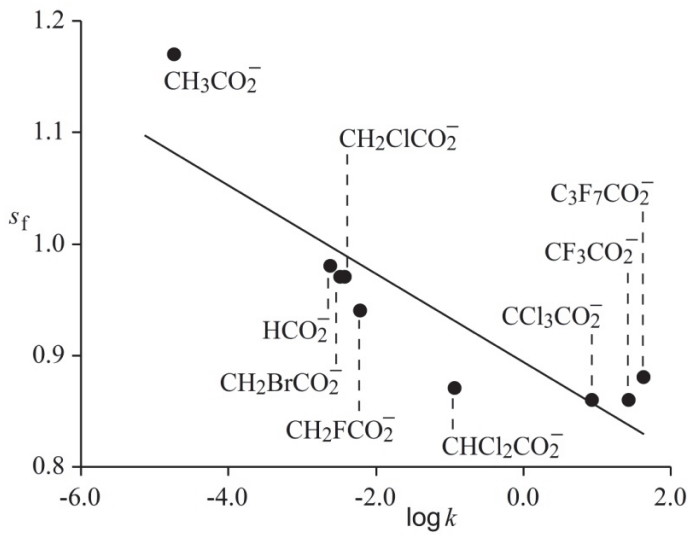

Figure 2. Correlation of $s_{\mathrm{f}}$ values of some aliphatic carboxylates against $\log k\left(25^{\circ} \mathrm{C}\right)$ for hydrolysis of the corresponding dianisylmethyl carboxylates in $60 \%$ acetone. Data for acetate, trifluoroacetate and heptafluorobutyrate were taken from Reference 5.

$\%$ aq. acetonitrile), Figure 2 indicates that the overall trend of decreasing $s_{\mathrm{f}}$ parameter with increasing reactivity exists and is comparable to that obtained for solvolysis of carboxylates in aqueous ethanol mixtures (correlation lines obtained in $80 \%$ and $60 \%$ aq. acetonitrile are presented in the Supporting Information). ${ }^{3}$ The correlation lines are as follow:

$s_{\mathrm{f}}=-0.040 \log k+0.894$ (60\% aq. acetone)

$s_{\mathrm{f}}=-0.028 \log k+0.922$ (80\% aq. acetonitrile)

$s_{\mathrm{f}}=-0.023 \log k+0.894$ (60\% aq. acetonitrile)

It turned out that the slope parameter $s_{\mathrm{f}}$ decreases for about $0.02-0.04$ if the reactivity of a substrate increases one order of magnitude. The similar trend has been obtained earlier for ethanolic solvents $(0.03-0.05$ per one order of magnitude). ${ }^{3}$ From the log $k$ vs. $s_{\mathrm{f}}$ correlation lines, the $s_{\mathrm{f}}$ parameters for isobutyrate and pivalate have been estimated and they are presented in Table 2.

Kinetic data obtained in this work indicate that the relative reactivities of the carboxylates investigated here are similar as in ethanolic solvents. Thus, it can be concluded that in the mixtures of water and aprotic solvents, the most important parameter that determines the relative reactivity of carboxylate leaving groups is the inductive effect of the substituents attached onto the carboxylate moiety, similarly as in ethanolic solvents. ${ }^{3}$

\section{Verification of the Method for Determining the Heterolysis Rate in Water/Aprotic Solvent Mixtures}

The next step has been to find out whether the above described method that uses the model reaction (presented in Scheme 1) can be applied for determining the reactivity of any carboxylate in the solvents used here.

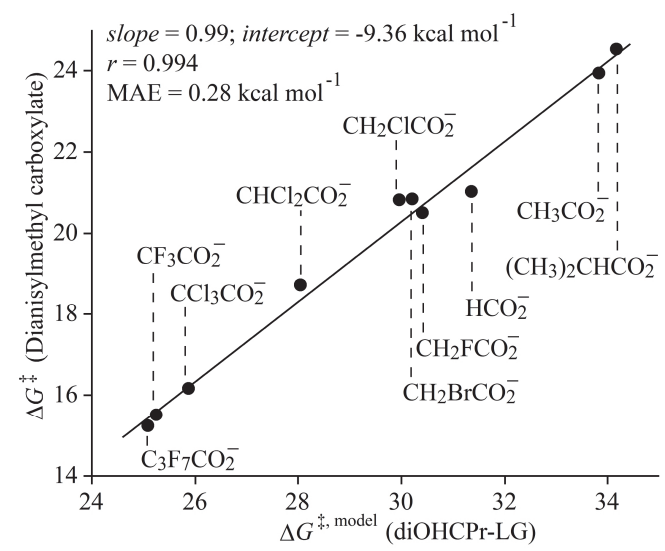

Figure 3. Correlation of experimental free energies of activation (in kcal mol${ }^{-1}$ ) for hydrolysis of dianisylmethyl carboxylates in $60 \%$ acetone versus free energies of activation (in kcal $\mathrm{mol}^{-1}$ ) for heterolysis of cis-2,3-dihydroxycyclopropyl trans-carboxylates calculated at the M06-2X/AUG-cc-pVTZ level of theory in the presence of the IEFPCM solvation model ( solvent $=$ water; data for $\Delta G^{\ddagger}$,model were taken from Reference 6).

The experimental barriers for solvolysis of 11 reference dianisylmethyl carboxylates $\left(\Delta G^{\text {,exp }}\right)$ in $60 \%$ aq. acetone, $80 \%$ and $60 \%$ aq. acetonitrile, respectively, have been plotted against the calculated free energies of activation $\left(\Delta G^{\ddagger \text {,model }}\right.$ ) obtained by quantum chemical calculations of the $\sigma$-assisted heterolytic displacement reaction (Scheme 1) in the presence of the IEFPCM solvation model. The data for $\left(\Delta G^{\text {t,model }}\right)$ have been taken from Reference 6 . The plot obtained for $60 \%$ aq. acetone is presented in Figure 3, while correlations plots for $60 \%$ and $80 \%$ aq. acetonitrile are presented in the Supporting Information.

According to the statistical parameters given in Table 3 , the correlation for each solvent mixture yields a very good linear fit, verifying the accuracy of the model for calculating solvolytic reactivity of carboxylates. The mean absolute errors (MAE) of regression for these three solvents of $0.28-0.33 \mathrm{kcal} \mathrm{mol}^{-1}$ fall within the same range as those obtained for the correlation between the same set of $\Delta G^{\ddagger \text {,model }}$ values and the experimental barriers measured in aqueous ethanol binary mixtures $(0.24-0.30$ kcal mol$\left.{ }^{-1}\right) .{ }^{6}$ This indicates that the specific solvation effects do not play a significant role in determining the relative reactivities of aliphatic carboxylates, enabling the use of the model reaction in which the IEFPCM model is applied for mimicking solvation effects. In analyzing the values of MAE for all solvents, it should also be taken into account that the both set of barriers used in the correlation (experimental solvolytic and $\Delta G^{\star \text {,model }}$ ) cover the ranges of as much as $10 \mathrm{kcal} \mathrm{mol}^{-1}$. Furthermore, the slopes of the correlation lines close to unity indicate that the model reaction is suitable to predict relative reactivities of carboxylates in solvolysis. 
Table 3. Statistical data for the correlation of $\Delta G^{\ddagger}$ for hydrolysis of dianisylmethyl carboxylates in different solvents with the corresponding $\Delta G^{\ddagger \text {,model }}$ obtained at the IEFPCM-M062X/AUG-cc-pVTZ level of theory

\begin{tabular}{|c|c|c|c|c|c|}
\hline Solve & Slope ${ }^{(b)}$ & Inte & $r^{(\mathrm{d})}$ & $\mathrm{MAE}^{(\mathrm{c}, \mathrm{e})}$ & $n^{(\mathrm{f})}$ \\
\hline $60 \mathrm{~A} 40 \mathrm{~W}$ & $0.99 \pm$ & -9.36 & 0.994 & $\begin{array}{l}4 \quad 0.28 \\
4\end{array}$ & 10 \\
\hline $0 \mathrm{~A}$ & 4 & -10.6 & 4 & 0. & 10 \\
\hline 0AN4 & $1.00 \pm$ & -10.10 & 0.994 & $4 \quad 0.30$ & 11 \\
\hline
\end{tabular}

(a) Binary solvents are expressed as volume fractions at $25^{\circ} \mathrm{C}$ : $\mathrm{A}=$ acetone, $\mathrm{AN}=$ acetonitrile, $\mathrm{W}=$ water. Free energies of activation for the model reaction $\left(\Delta G^{\dagger, \text { model }}\right)$ used in correlations are given in Table S3 of Reference 6.

(b) Errors shown are standard errors.

(c) In kcal mol ${ }^{-1}$

(d) Correlation coefficient.

(e) Mean absolute error.

(f) The number of correlation data points. Experimental $\Delta G^{\ddagger}$ for solvolysis of acetate in all solvents used were taken from Reference 5. Experimental $\Delta G^{\star}$ for solvolysis of heptafluorobutyrate and trifluoroacetate in $60 \mathrm{~A} 40 \mathrm{~W}$ were taken from Reference 2 .

Additional verification of the method can be acquired examining individual deviations of the calculated kinetic parameters $\left(\log k^{\text {calc }}, s_{\mathrm{f}}^{\text {estim }}\right.$, and $\left.N_{\mathrm{f}}^{\text {calc }}\right)$ from the experimental values given in Tables 1 and 2. Therefore, from the $\Delta G^{\ddagger, \exp } / \Delta G^{\ddagger \text {,model }}$ correlation plots (Table 3, Figure 3), $\log k^{\text {calc }}$ for 11 reference dianisylmethyl carboxylates have been determined according to the equation: $\Delta G^{\ddagger \text {,model }}=R T\left[\ln \left(k_{\mathrm{B}} / h\right)-\ln \left(k^{\text {calc }} / T\right)\right.$ in which $k_{\mathrm{B}}$ is the Boltzmann constant, $h$ is the Planck constant, and $R$ is the gas constant. Also, from the correlations given with Equations $2, s_{\mathrm{f}}^{\text {estim }}$ for the reference carboxylate leaving groups have been estimated for $60 \%$ aq. acetone, $80 \%$ aq. acetonitrile and $60 \%$ aq. acetonitrile, and compared with the experimental values. Finally, from $\log k^{\text {calc }}$ and the corresponding $S_{\mathrm{f}}^{\text {estim }}$, values for $N_{\mathrm{f}}^{\text {calc }}$ for the reference carboxylates have been calculated using Equation 1, and also compared with the corresponding experimental values in the terms of individual deviations. All calculated kinetic parameters $\left(\log k^{\text {calc }}, s_{\mathrm{f}}^{\text {estim }}\right.$, and $\left.N_{\mathrm{f}}^{\text {calc }}\right)$ and the individual deviations are presented in Table 4. To make the comparison between the calculated and experimental values easier, from the individual deviations given in Table 4, the mean absolute errors (MAE) have been calculated for both $\log k^{\text {calc }}$ and $N_{\mathrm{f}}^{\text {calc }}$ values for each of three aqueous solvents. MAEs for $\log k^{\text {calc }}$ and $N_{\mathrm{f}}^{\text {calc }}$ in $60 \%$ aq. acetone, $80 \%$ aq. acetonitrile and $60 \%$ aq. acetonitrile are essentially the same $\left(\log k^{\text {calc }}: 0.21,0.24\right.$ and 0.22 ; $N_{\mathrm{f}}^{\text {calc }}: 0.22,0.24$ and 0.26 , respectively), showing that the contribution of $s_{\mathrm{f}}^{\text {estim }}$ to the error in $N_{\mathrm{f}}^{\text {calc }}$ is negligible. Indeed, the comparison between the experimental and estimated $s_{\mathrm{f}}$ values given in Table 4 reveals agreements in the limits of experimental error, verifying the validity of method for calculating $s_{\mathrm{f}}^{\text {estim }}$ values by Equa- tions 2. MAEs for $N_{\mathrm{f}}^{\text {calc }}$ values, which are in average for $0.1-0.2$ larger than the standard errors for the experimental $N_{\mathrm{f}}$ values given in Table 2, can be taken as a verification of the suitability of the model used. Also the fact that the range of nucleofugalities for carboxylates determined here for each solvent is about 7 units, while the corresponding MAEs are $0.22,0.24$, and 0.26 , respectively, represents a further proof for reliability of the presented model for the semiquantitative determination of the solvolytic reactivity of a given carboxylate.

\section{Reactivity of Other Carboxylates}

Once a method has been verified, we have estimated barriers and rate constants for solvolysis of 34 other dianisylmethyl carboxylates in aqueous acetonitrile and acetone. We used the computed $\Delta G^{\ddagger \text {,model }}$ values for 34 different 2,3-dihydroxycyclopropyl trans-carboxylates (published in Reference 6) to interpolate and extrapolate the Gibbs free energies of activation (in a given solvent) for solvolysis of the corresponding 34 dianisylmethyl carboxylates from the $\Delta G^{\ddagger \text {,exp }}$ vs. $\Delta G^{\ddagger \text {,model }}$ correlation lines presented above (Figure 3 and Table 3 ). The estimated reaction rates of various dianisylmethyl carboxylates in $60 \%$, and $80 \%$ aqueous acetonitrile and in 60 $\%$ aqueous acetone are given in Table 5 . The linear correlations between the logarithms of solvolysis rates and the $s_{\mathrm{f}}$ parameters (given by Equations $2 \mathrm{a}, 2 \mathrm{~b}$, and $2 c)$ enabled estimating the slope parameter $\left(s_{\mathrm{f}}^{\text {estim }}\right)$ of a given nucleofuge in a given solvent. Similarly, as it is presented above, from the rate constants $\left(\log k^{\text {calc }}\right)$ for dianisylmethyl derivatives and the corresponding $s_{\mathrm{f}}^{\text {estim }}$ parameters, the nucleofugality for each new carboxylate in aprotic solvents/water mixtures has been determined from Equation 1. The results are presented in Table 5.

In Figure 4 the nucleofugalities of the aliphatic carboxylates determined here in $60 \%$ aq. acetone (experimental and calculated) are compared with nucleofugalities of some selected leaving groups published earlier. For example, it can be seen that the most reactive carboxylate leaving group examined here is trinitroacetate, while the least reactive is the malonate leaving group. Further, monohalogenated acetates fall in a narrow range of reactivity between $p$-nitrobenzoate and 3,5-dinitrobenzoate. Figure 4 also shows that the effects of the substituents are cumulative. Each additional halogen atom (experimental $N_{\mathrm{f}}$ ) or nitro group (calculated $N_{\mathrm{f}}$ ) introduced onto the carboxylate moiety increases the nucleofugality for approximately the same number of units of $N_{\mathrm{f}}$, due to more pronounced inductive effects.

In summary, nucleofugalities (experimental and calculated) are now available for more than forty different aliphatic carboxylates in aqueous ethanol, ${ }^{3}$ acetone and acetonitrile, which together with nucleofugalities of substituted benzoates determined earlier, ${ }^{10}$ constitute an 
Table 4. Calculated solvolytic reactivities for the reference dianisylmethyl carboxylates and the corresponding calculated nucleofugalities of carboxylate leaving groups

\begin{tabular}{|c|c|c|c|c|c|}
\hline Solvent ${ }^{\text {(a) }}$ & Carboxylate & $\Delta G^{\ddagger \text {,calc (b) }}$ & $\log k^{\text {calc (c) }}$ & $s_{\mathrm{f}}^{\text {estim }(\mathrm{d})}$ & $N_{\mathrm{f}}^{\text {calc (e) }}$ \\
\hline \multirow[t]{10}{*}{$60 \mathrm{~A} 40 \mathrm{~W}$} & 2-Methylpropanoate & 24.47 & $-5.14(+0.04)$ & $1.10( \pm 0.00)$ & $-4.68(+0.03)$ \\
\hline & Acetate $^{(\mathrm{f})}$ & 24.13 & $-4.89(-0.15)$ & $1.09(-0.08)$ & $-4.49(-0.44)$ \\
\hline & Formate & 21.69 & $-3.11(-0.50)$ & $1.02(+0.04)$ & $-3.04(-0.34)$ \\
\hline & Fluoroacetate & 20.76 & $-2.42(-0.20)$ & $0.99(+0.05)$ & $-2.45(-0.05)$ \\
\hline & Chloroacetate & 20.31 & $-2.09(+0.37)$ & $0.98(+0.01)$ & $-2.14(+0.45)$ \\
\hline & Bromoacetate & 20.55 & $-2.27(+0.20)$ & $0.98(+0.01)$ & $-2.32(+0.28)$ \\
\hline & Dichloroacetate & 18.40 & $-0.69(+0.24)$ & $0.92(+0.05)$ & $-0.75(+0.32)$ \\
\hline & Trifluoroacetate ${ }^{(\mathrm{f})}$ & 15.64 & $1.33(-0.10)$ & $0.84(-0.02)$ & $1.58(-0.08)$ \\
\hline & Trichloroacetate & 16.26 & $0.87(-0.07)$ & $0.86( \pm 0.00)$ & $1.02(-0.07)$ \\
\hline & Heptafluorobutanoate ${ }^{(\mathrm{f})}$ & 15.49 & $1.44(-0.20)$ & $0.84(-0.04)$ & $1.71(-0.15)$ \\
\hline \multirow[t]{10}{*}{ 80AN20W } & 2-Methylpropanoate & 25.20 & $-5.68(-0.13)$ & $1.08( \pm 0.00)$ & $-5.26(-0.12)$ \\
\hline & Acetate $^{(\mathrm{f})}$ & 24.84 & $-5.41(-0.36)$ & $1.07(-0.04)$ & $-5.06(-0.54)$ \\
\hline & Formate & 22.25 & $-3.52(-0.42)$ & $1.02(+0.03)$ & $-3.45(-0.29)$ \\
\hline & Fluoroacetate & 21.26 & $-2.79(-0.10)$ & $1.00(+0.02)$ & $-2.79(-0.02)$ \\
\hline & Chloroacetate & 20.79 & $-2.45(+0.43)$ & $0.99(-0.02)$ & $-2.47(+0.39)$ \\
\hline & Bromoacetate & 21.04 & $-2.63(+0.27)$ & $1.00( \pm 0.00)$ & $-2.63(+0.29)$ \\
\hline & Dichloroacetate & 18.76 & $-0.96(+0.13)$ & $0.95(+0.03)$ & $-1.01(+0.17)$ \\
\hline & Trifluoroacetate & 15.83 & $1.19(-0.15)$ & $0.89(-0.01)$ & $1.34(-0.15)$ \\
\hline & Trichloroacetate & 16.49 & $0.71(-0.01)$ & $0.90(+0.06)$ & $0.78(-0.08)$ \\
\hline & Heptafluorobutanoate & 15.68 & $1.30(-0.43)$ & $0.89(-0.05)$ & $1.46(-0.38)$ \\
\hline \multirow[t]{11}{*}{$60 \mathrm{AN} 40 \mathrm{~W}$} & 2,2-Dimethylpropanoate & 24.72 & $-5.33(+0.10)$ & $1.02( \pm 0.00)$ & $-5.22(+0.10)$ \\
\hline & 2-Methylpropanoate & 24.07 & $-4.85(+0.12)$ & $1.01( \pm 0.00)$ & $-4.80(+0.12)$ \\
\hline & Acetate $^{(\mathrm{f})}$ & 23.73 & $-4.60(-0.09)$ & $1.00(-0.08)$ & $-4.60(-0.42)$ \\
\hline & Formate & 21.26 & $-2.79(-0.34)$ & $0.96(+0.03)$ & $-2.91(-0.24)$ \\
\hline & Fluoroacetate & 20.32 & $-2.10(+0.04)$ & $0.94(+0.03)$ & $-2.24(+0.14)$ \\
\hline & Chloroacetate & 19.87 & $-1.77(+0.60)$ & $0.93( \pm 0.00)$ & $-1.90(+0.68)$ \\
\hline & Bromoacetate & 20.11 & $-1.95(+0.43)$ & $0.94(+0.01)$ & $-2.07(+0.53)$ \\
\hline & Dichloroacetate & 17.94 & $-0.36(+0.38)$ & $0.90(+0.05)$ & $-0.40(+0.47)$ \\
\hline & Trifluoroacetate & 15.15 & $1.69(+0.06)$ & $0.86( \pm 0.00)$ & $1.96(+0.06)$ \\
\hline & Trichloroacetate & 15.78 & $1.23(-0.10)$ & $0.87(-0.02)$ & $1.41(-0.08)$ \\
\hline & Heptafluorobutanoate & 15.00 & $1.80(-0.12)$ & $0.85(-0.04)$ & $2.12(-0.04)$ \\
\hline
\end{tabular}

(a) Binary solvents are expressed as volume fractions at $25^{\circ} \mathrm{C}$ : $\mathrm{A}=$ acetone, $\mathrm{AN}=$ acetonitrile, $\mathrm{W}=$ water.

(b) In kcal mol ${ }^{-1}$. Obtained from the $\Delta G^{\ddagger}$ (dianisylmethyl carboxylates) versus $\Delta G^{\ddagger \text {,model }}$ (M06-2X/AUG-cc-pVTZ level) correlation plots. Data for $\Delta G^{\ddagger \text {,model }}\left(25^{\circ} \mathrm{C}\right)$ values for cis-2,3-dihydroxycyclopropyl trans-carboxylates were taken from Reference 6 .

(c) Logarithms of solvolytic first-order rate constants at $25^{\circ} \mathrm{C}$ obtained from the corresponding $\Delta G^{\ddagger}$,calc values. Deviations from experimental values $\left(\log k^{\text {calc }}-\log k\right)$ are given in parentheses.

(d) $S$ parameters estimated from the correlation of $s$ versus $\log k\left(25^{\circ} \mathrm{C}\right)$ for solvolysis of dianisylmethyl carboxylates in an appropriate solvent (Equations 2a, 2b, and 2c). Deviations from experimental $s \mathrm{f}$ values $\left(s_{\mathrm{f}}^{\text {estim }}-s_{\mathrm{f}}\right)$ are given in parentheses.

(e) Calculated from $\log k^{\text {calc }}$ and appropriate $s_{\mathrm{f}}^{\text {estim }}$ using Equation 1. $E_{\mathrm{f}}$ value for the dianisylmethyl electrofuge is 0.00 . Deviations from experimental values $\left(N_{\mathrm{f}}^{\text {calc }}-N_{\mathrm{f}}\right)$ are given in parentheses.

(f) Experimental data are given in Reference 5 .

impressive group of more than hundred carboxylates, whose reactivities are assessed. From the nucleofugespecific parameters of those carboxylate leaving groups, and the published $E_{\mathrm{f}}$ parameters for numerous electro- fuges, ${ }^{5,11}$ the rate of the corresponding electrofugecarboxylate substrate can be estimated semiquantitatively using Equation 1. Also, the reactivity of any carboxylate that have not yet been encompassed into the 
Table 5. Calculated logarithms of rate constants for hydrolysis of modeled dianisylmethyl carboxylates at $25{ }^{\circ} \mathrm{C}$ and related calculated nucleofugality parameters

\begin{tabular}{|c|c|c|c|c|c|c|}
\hline \multirow{2}{*}{ Carboxylate } & \multicolumn{2}{|c|}{$60 \mathrm{~A} 40 \mathrm{~W}^{\text {(a) }}$} & \multicolumn{2}{|c|}{ 80AN20W (a) } & \multicolumn{2}{|c|}{ 60AN40W ${ }^{\text {(a) }}$} \\
\hline & $\log k^{\text {calc (b) }}$ & $N_{\mathrm{f}}^{\text {calc (c) }}\left(s_{\mathrm{f}}^{\text {estim }}\right)^{(\mathrm{d})}$ & $\log k^{\text {calc (b) }}$ & $N_{\mathrm{f}}^{\text {calc (c) }}\left(s_{\mathrm{f}}^{\text {estim }}\right)^{(\mathrm{d})}$ & $\log k^{\text {calc (b) }}$ & $N_{\mathrm{f}}^{\text {calc (c) }}\left(s_{\mathrm{f}}^{\text {estim }}\right)^{(\mathrm{d})}$ \\
\hline 2,2-Dimethylpropanoate & -5.61 & $-5.01(1.12)$ & -6.18 & $-5.67(1.09)$ & - & - \\
\hline Propanoate & -4.68 & $-4.33(1.08)$ & -5.19 & $-4.85(1.07)$ & -4.39 & $-4.43(0.99)$ \\
\hline Butanoate & -5.02 & $-4.60(1.09)$ & -5.55 & $-5.14(1.08)$ & -4.73 & $-4.73(1.00)$ \\
\hline Phenylacetate & -4.10 & $-3.86(1.06)$ & -4.57 & $-4.35(1.05)$ & -3.79 & $-3.87(0.98)$ \\
\hline Propenoate & -3.93 & $-3.75(1.05)$ & -4.40 & $-4.19(1.05)$ & -3.63 & $-3.71(0.98)$ \\
\hline Propynoate & -1.40 & $-1.47(0.95)$ & -1.71 & $-1.76(0.97)$ & -1.07 & $-1.16(0.92)$ \\
\hline Difluoroacetate & -0.37 & $-0.41(0.91)$ & -0.62 & $-0.66(0.94)$ & -0.03 & $-0.04(0.89)$ \\
\hline Dibromoacetate & -0.20 & $-0.23(0.90)$ & -0.44 & $-0.47(0.93)$ & 0.14 & $0.16(0.89)$ \\
\hline Tribromoacetate & 0.64 & $0.74(0.87)$ & 0.46 & $0.50(0.91)$ & 0.99 & $1.14(0.87)$ \\
\hline Pentafluoropropanoate & 1.42 & $1.70(0.84)$ & 1.29 & $1.44(0.89)$ & 1.78 & $2.10(0.85)$ \\
\hline Pentachloropropanoate & 0.66 & $0.76(0.87)$ & 0.48 & $0.53(0.91)$ & 1.01 & $1.17(0.87)$ \\
\hline Pentabromopropanoate & 0.44 & $0.50(0.88)$ & 0.25 & $0.28(0.91)$ & 0.79 & $0.90(0.88)$ \\
\hline Heptachlorobutanoate & 0.65 & $0.75(0.87)$ & 0.47 & $0.52(0.91)$ & 1.01 & $1.16(0.87)$ \\
\hline 3,3,3-Trifluoropropanoate & -2.06 & $-2.11(0.98)$ & -2.42 & $-2.44(0.99)$ & -1.74 & $-1.87(0.93)$ \\
\hline Hexafluoroisobutanoate & -0.75 & $-0.82(0.92)$ & -1.02 & $-1.08(0.95)$ & -0.42 & $-0.46(0.90)$ \\
\hline Nonafluorotrimethylacetate & 1.90 & $2.32(0.82)$ & 1.80 & $2.07(0.87)$ & 2.27 & $2.70(0.84)$ \\
\hline Cyanoacetate & -1.42 & $-1.49(0.95)$ & -1.73 & $-1.79(0.97)$ & -1.09 & $-1.18(0.92)$ \\
\hline Dicyanoacetate & 1.78 & $2.17(0.82)$ & 1.66 & $1.89(0.88)$ & 2.14 & $2.54(0.84)$ \\
\hline Tricyanoacetate & 4.68 & $6.59(0.71)$ & 4.74 & $6.00(0.79)$ & 5.07 & $6.50(0.78)$ \\
\hline Nitroacetate & -0.44 & $-0.49(0.91)$ & -0.69 & $-0.74(0.94)$ & -0.10 & $-0.11(0.90)$ \\
\hline Dinitroacetate & 2.61 & $3.31(0.79)$ & 2.55 & $3.00(0.85)$ & 2.99 & $3.60(0.83)$ \\
\hline Trinitroacetate & 5.42 & $7.97(0.68)$ & 5.52 & $7.17(0.77)$ & 5.82 & $7.65(0.76)$ \\
\hline 2-Cyanopropenoate & -1.12 & $-1.19(0.94)$ & -1.41 & $-1.47(0.96)$ & -0.79 & $-0.87(0.91)$ \\
\hline 2-Hydroxyethanoate & -2.64 & $-2.64(1.00)$ & -3.03 & $-3.00(1.01)$ & -2.33 & $-2.45(0.95)$ \\
\hline 2-Hydroxypropanoate & -2.92 & $-2.89(1.01)$ & -3.33 & $-3.26(1.02)$ & -2.61 & $-2.74(0.95)$ \\
\hline 2,3-Dihydroxypropanoate & -2.45 & $-2.47(0.99)$ & -2.81 & $-2.81(1.00)$ & -2.12 & $-2.26(0.94)$ \\
\hline Oxoethanoate & -0.45 & $-0.50(0.91)$ & -0.71 & $-0.75(0.94)$ & -0.11 & $-0.13(0.90)$ \\
\hline 2-Oxopropanoate & -1.78 & $-1.83(0.97)$ & -2.12 & $-2.16(0.98)$ & -1.46 & $-1.57(0.93)$ \\
\hline 3-Oxopropanoate & -4.01 & $-3.82(1.05)$ & -4.48 & $-4.27(1.05)$ & -3.71 & $-3.79(0.98)$ \\
\hline 2-Oxobutanoate & -2.04 & $-2.08(0.98)$ & -2.39 & $-2.42(0.99)$ & -1.72 & $-1.85(0.93)$ \\
\hline 3-Oxobutanoate & -3.96 & $-3.77(1.05)$ & -4.42 & $-4.21(1.05)$ & -3.66 & $-3.73(0.98)$ \\
\hline Oxalate, 1. dissociation & -0.86 & $-0.93(0.93)$ & -1.13 & $-1.19(0.95)$ & -0.53 & $-0.58(0.91)$ \\
\hline Oxalate, 2. dissociation & -4.98 & $-4.57(1.09)$ & -5.51 & $-5.10(1.08)$ & -4.69 & $-4.69(1.00)$ \\
\hline Malonate, 1. dissociation & -3.49 & $-3.39(1.03)$ & -3.92 & $-3.81(1.03)$ & -3.18 & $-3.28(0.97)$ \\
\hline Malonate, 2. dissociation & -6.24 & $-5.47(1.14)$ & -6.84 & $-6.16(1.11)$ & -5.96 & $-5.78(1.03)$ \\
\hline
\end{tabular}

(a) Binary solvents are expressed as volume fractions at $25^{\circ} \mathrm{C}$ : $\mathrm{A}=$ acetone, $\mathrm{AN}=$ acetonitrile, $\mathrm{W}=$ water.

(b) Logarithms of solvolytic first-order rate constants at $25^{\circ} \mathrm{C}$ obtained from $\Delta G^{\ddagger \text {,calc }}$ values, which are estimated from the correlation of experimental solvolysis $\Delta G^{\ddagger}\left(25^{\circ} \mathrm{C}\right)$ for dianisylmethyl carboxylates versus heterolytic $\Delta G^{\ddagger}$,model $\left(25^{\circ} \mathrm{C}\right)$ for cis-2,3dihydroxycyclopropyl trans-carboxylates calculated at the IEFPCM-M06-2X/AUG-cc-pVTZ level of theory. Parameters of correlation lines are given in Table 3. $\Delta G^{\ddagger \text {,model }}\left(25^{\circ} \mathrm{C}\right)$ values used for the correlation were taken from Reference 6.

(c) Calculated from $\log k^{\text {calc }}$ and appropriate $s_{\mathrm{f}}^{\text {estim }}$ using Equation 1. $E_{\mathrm{f}}$ value for the dianisylmethyl electrofuge is 0.00 .

(d) $S \mathrm{f}$ values estimated from the correlation plot of $s \mathrm{f}$ versus $\log k\left(25^{\circ} \mathrm{C}\right)$ for solvolysis of dianisylmethyl carboxylates in an appropriate solvent (Equations 2a, 2b, 2c). 


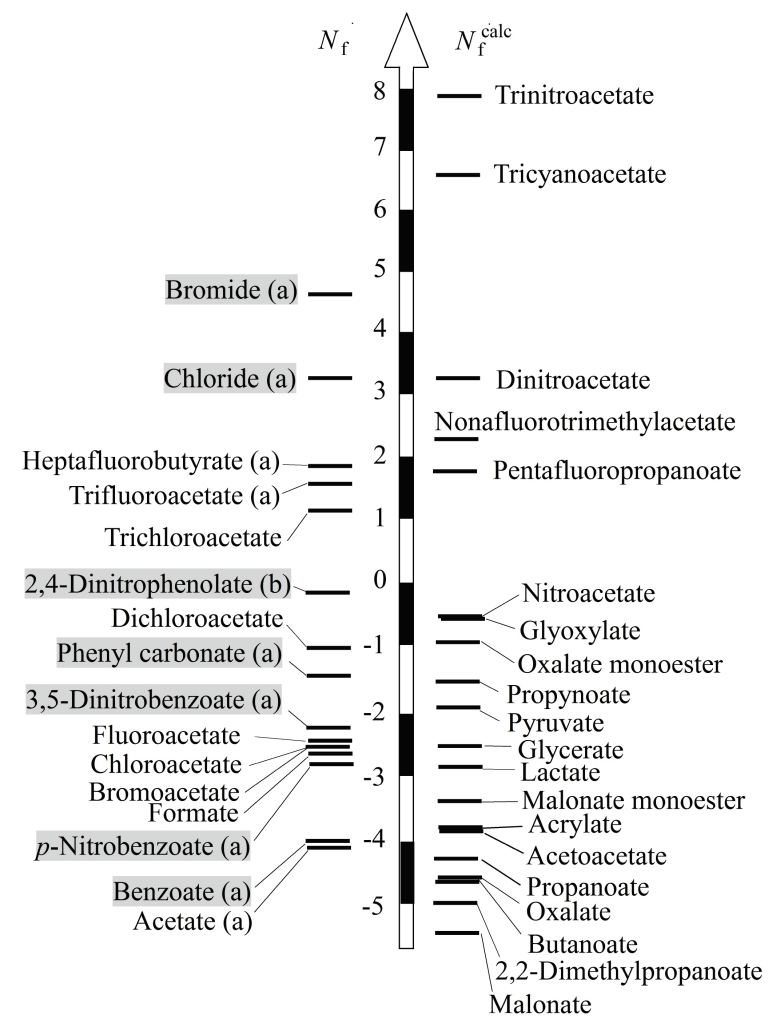

Figure 4. Experimental and calculated nucleofugalities of some aliphatic carboxylates in $60 \%$ acetone compared with nucleofugalities of some selected leaving groups (shaded; data for $\mathrm{a}$ and $\mathrm{b}$ were taken from References 5 and 9, respectively).

nucleofugality scale can be estimated by interpolation/extrapolation of the computed barrier from the given $\Delta G^{\ddagger \text {,exp }}$ versus $\Delta G^{\ddagger \text {,model }}$ correlation line. In predicting the reactivities of aliphatic carboxylates, the model reaction presented in Scheme 1 (established in Reference 6) turned out to be suitable, while for benzoates it is the $n$-assisted displacement reaction starting with negatively charged 2-oxyethyl benzoates (established in Reference 10a).

Supplementary Materials. - Supporting informations to the paper are enclosed to the electronic version of the article. These data can be found on the website of Croatica Chemica Acta (http://public.carnet.hr/ccacaa).

Acknowledgements. This work has been fully supported by the Croatian Science Foundation under the project 1021.

\section{REFERENCES}

1. (a) D. Farcasiu, J. Jaehme, and C. Rüchardt, J. Am. Chem. Soc. 107 (1985) 5717-5722. (b) T. W. Bentley and K. Roberts, J. Chem. Soc. Perkin Trans. 2 (1989) 1055-1060. (c) D. N. Kevill and A. R. Pinhas, J. Org. Chem. 58 (1993) 197-201. (d) B. Denegri and O. Kronja, Croat. Chem. Acta 83 (2010) 223-226.

2. B. Denegri and O. Kronja, J. Org. Chem. 74 (2009) 5927-5933.

3. M. Matić, B. Denegri, and O. Kronja, Eur. J. Org. Chem. (2014) 1477-1486.

4. (a) B. Denegri, A. Streiter, S. Jurić, A. R. Ofial, O. Kronja, and H. Mayr, Chem. Eur. J. 12 (2006) 1648-1656. (b) Correction: B. Denegri, A. Streiter, S. Jurić, A. R. Ofial, O. Kronja, and H. Mayr, Chem. Eur. J. 12 (2006) 5415-5415. (c) B. Denegri, S. Minegishi, O. Kronja, and H. Mayr, Angew. Chem. Int. Ed. 43 (2004) 2302-2305.

5. N. Streidl, B. Denegri, O. Kronja, and H. Mayr, Acc. Chem. Res. 43 (2010) 1537-1549.

6. B. Denegri, M. Matić, and O. Kronja, Org. Biomol. Chem. 12 (2014) 5698-5709.

7. Y. Zhao, D. G. Truhlar, Theor. Chem. Acc. 120 (2008) 215-241.

8. (a) J. Tomasi, B. Mennucci, E. Cancès, J. Mol. Struct. (Theochem) 464 (1999) 211-226. (b) J. Tomasi, B. Mennucci, R. Cammi, Chem. Rev. 105 (2005), 2999-3093.

9. M. Matić, B. Denegri, and O. Kronja, Eur. J. Org. Chem. (2010) 6019-6024.

10. (a) M. Matić, B. Denegri, and O. Kronja, J. Org. Chem. 77 (2012) 8986-8998. (b) M. Matić, B. Denegri, and O. Kronja, Croat. Chem. Acta. 85 (2012) 585-594.

11. B. Denegri, A. R. Ofial, S. Jurić, A. Streiter, O. Kronja, and H. Mayr, Chem. Eur. J. 12 (2006) 1657-1666. 


\section{SUPPLEMENTARY MATERIALS}

\section{$s_{\mathrm{f}}$ Versus $\log k$ Correlation Plots}

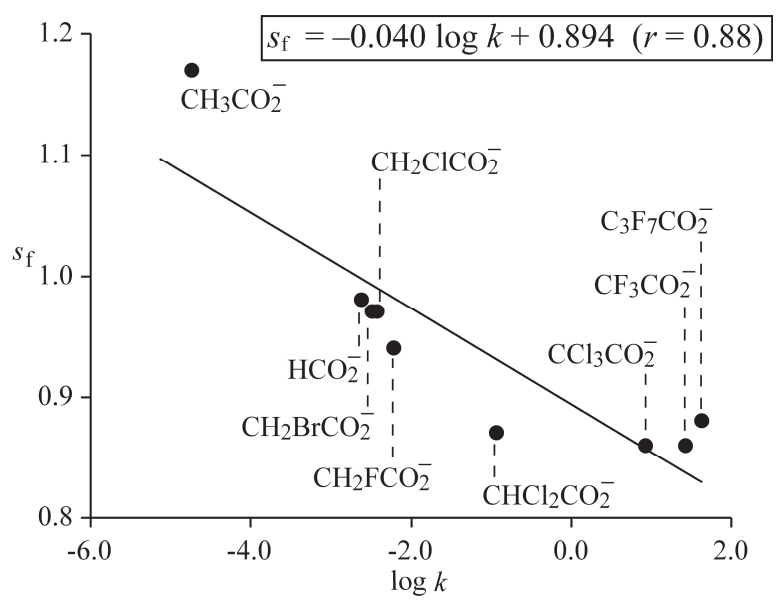

Figure S1. Correlation of $s \mathrm{f}$ values of some aliphatic carboxylates against $\log k\left(25^{\circ} \mathrm{C}\right)$ for hydrolysis of the corresponding dianisylmethyl carboxylates in $60 \%$ acetone.

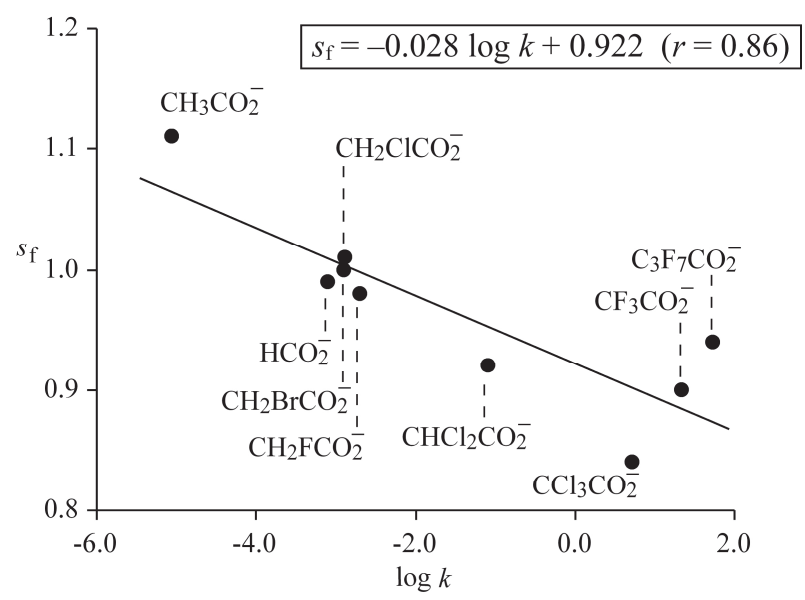

Figure S2. Correlation of $s_{\mathrm{f}}$ values of some aliphatic carboxylates against $\log k\left(25^{\circ} \mathrm{C}\right)$ for hydrolysis of the corresponding dianisylmethyl carboxylates in $80 \%$ acetonitrile.

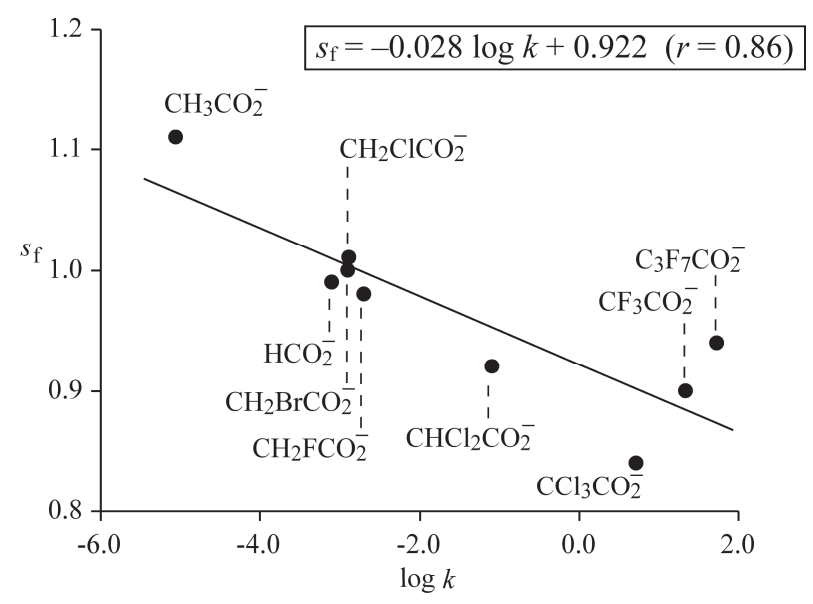

Figure S3. Correlation of $s \mathrm{f}$ values of some aliphatic carboxylates against $\log k\left(25^{\circ} \mathrm{C}\right)$ for hydrolysis of the corresponding dianisylmethyl carboxylates in $60 \%$ acetonitrile. 
Table S1. $s \mathrm{f}$ values of some carboxylate leaving groups and $\log k$ values for hydrolysis of the corresponding dianisylmethyl carboxylates

\begin{tabular}{|c|c|c|c|}
\hline Solvent ${ }^{\text {(a) }}$ & Carboxylate & $S \mathrm{f}$ & $\log k$ \\
\hline \multirow[t]{9}{*}{$60 \mathrm{~A} 40 \mathrm{~W}$} & Acetate $^{(\mathrm{b}, \mathrm{c})}$ & 1.17 & -4.74 \\
\hline & Formate & 0.98 & -2.61 \\
\hline & Fluoroacetate & 0.94 & -2.22 \\
\hline & Chloroacetate & 0.97 & -2.46 \\
\hline & Bromoacetate & 0.97 & -2.47 \\
\hline & Dichloroacetate $^{(\mathrm{c})}$ & 0.87 & -0.93 \\
\hline & Trifluoroacetate $^{(\mathrm{b}, \mathrm{c})}$ & 0.86 & 1.43 \\
\hline & Trichloroacetate ${ }^{(c)}$ & 0.86 & 0.94 \\
\hline & Heptafluorobutanoate ${ }^{(b, c)}$ & 0.88 & 1.64 \\
\hline \multirow[t]{9}{*}{ 80AN20W } & Acetate $^{(b)}$ & 1.11 & -5.05 \\
\hline & Formate & 0.99 & -3.10 \\
\hline & Fluoroacetate & 0.98 & -2.69 \\
\hline & Chloroacetate & 1.01 & -2.88 \\
\hline & Bromoacetate & 1.00 & -2.90 \\
\hline & Dichloroacetate $^{(c)}$ & 0.92 & -1.09 \\
\hline & Trifluoroacetate ${ }^{(c)}$ & 0.90 & 1.34 \\
\hline & Trichloroacetate ${ }^{(c)}$ & 0.84 & 0.72 \\
\hline & Heptafluorobutanoate ${ }^{(\mathrm{c})}$ & 0.94 & 1.73 \\
\hline \multirow{9}{*}{$60 \mathrm{AN} 40 \mathrm{~W}$} & Acetate $^{(b, c)}$ & 1.08 & -4.51 \\
\hline & Formate & 0.93 & -2.45 \\
\hline & Fluoroacetate & 0.91 & -2.14 \\
\hline & Chloroacetate & 0.93 & -2.37 \\
\hline & Bromoacetate & 0.93 & -2.38 \\
\hline & Dichloroacetate ${ }^{(c)}$ & 0.85 & -0.74 \\
\hline & Trifluoroacetate ${ }^{(\mathrm{c})}$ & 0.86 & 1.63 \\
\hline & Trichloroacetate ${ }^{(c)}$ & 0.89 & 1.33 \\
\hline & Heptafluorobutanoate ${ }^{(\mathrm{c})}$ & 0.89 & 1.92 \\
\hline
\end{tabular}

(a) Binary solvents are expressed as volume fractions at $25^{\circ} \mathrm{C}$ : $\mathrm{A}=$ acetone, $\mathrm{AN}=$ acetonitrile, $\mathrm{W}=$ water.

(b) $s_{\mathrm{f}}$ and $\log k$ values were taken from the reference: N. Streidl, B. Denegri, O. Kronja, and H. Mayr, Acc. Chem. Res. 43 (2010) $1537-1549$.

(c) $\log k$ was calculated using the equation $\log k\left(25^{\circ} \mathrm{C}\right)=s_{\mathrm{f}}\left(E_{\mathrm{f}}+N_{\mathrm{f}}\right)$ and appropriate nucleofugality parameters. $E_{\mathrm{f}}$ value for the dianisylmethyl electrofuge is 0.00 . 


\section{Correlation of Experimental Free Energies of Activation for Hydrolysis of Dianisylmethyl Carboxylates Versus Free Energies of Activation for the Model Reaction}

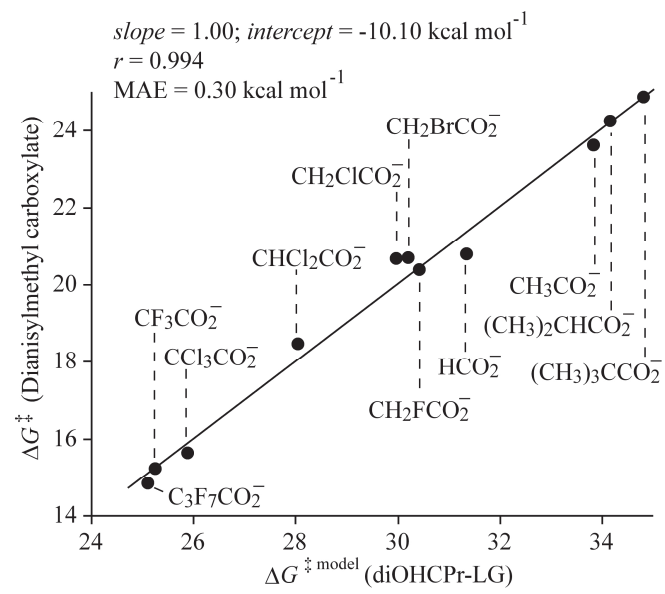

Figure S4. Correlation of experimental free energies of activation (in kcal mol ${ }^{-1}$ ) for hydrolysis of dianisylmethyl carboxylates in $60 \%$ acetonitrile versus free energies of activation (in $\mathrm{kcal} \mathrm{mol}^{-1}$ ) for heterolysis of cis-2,3-dihydroxycyclopropyl trans-carboxylates calculated at the M06-2X/AUG-cc-pVTZ level of theory in the presence of IEFPCM solvation model (solvent $=$ water; data for $\Delta G^{\ddagger \text {,model }}$ were taken from the reference: B. Denegri, M. Matić and O. Kronja, Org. Biomol. Chem. 12 (2014) 5698-5709.).

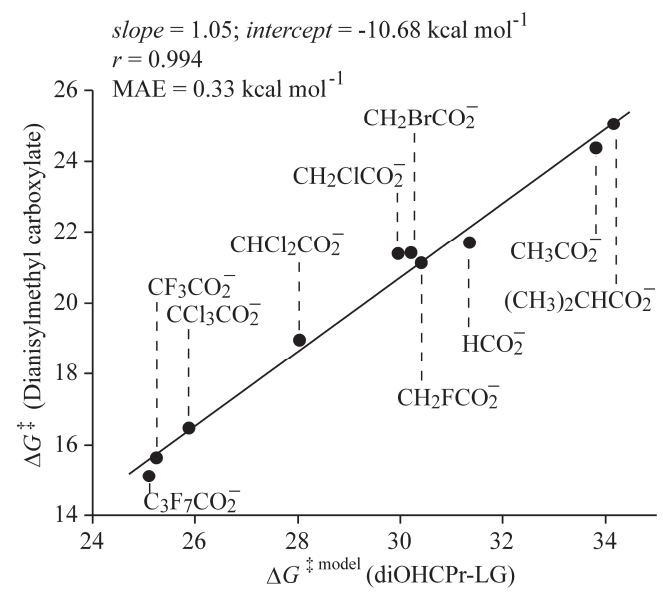

Figure S5. Correlation of experimental free energies of activation (in kcal mol ${ }^{-1}$ ) for hydrolysis of dianisylmethyl carboxylates in $\mathbf{8 0} \%$ acetonitrile versus free energies of activation (in $\mathrm{kcal} \mathrm{mol}^{-1}$ ) for heterolysis of cis-2,3-dihydroxycyclopropyl trans-carboxylates calculated at the M06-2X/AUG-cc-pVTZ level of theory in the presence of IEFPCM solvation model (solvent = water; data for $\Delta G^{\ddagger \text {,model }}$ were taken from the reference: B. Denegri, M. Matić and O. Kronja, Org. Biomol. Chem. 12 (2014) 5698-5709.). 
Table S2. Experimental log $k$ values and the corresponding free energies of activation (in $\mathrm{kcal} \mathrm{mol}^{-1}$ ) for hydrolysis of dianisylmethyl carboxylates

\begin{tabular}{|c|c|c|c|}
\hline Solvent ${ }^{(a)}$ & Carboxylate & $\log k$ & $\Delta G^{\ddagger, \exp }$ \\
\hline \multirow[t]{10}{*}{$60 \mathrm{~A} 40 \mathrm{~W}$} & Acetate $^{(\mathrm{b}, \mathrm{c})}$ & -4.74 & 23.92 \\
\hline & Formate & -2.61 & 21.01 \\
\hline & 2-Methylpropanoate & -5.18 & 24.52 \\
\hline & Fluoroacetate & -2.22 & 20.48 \\
\hline & Chloroacetate & -2.46 & 20.81 \\
\hline & Bromoacetate & -2.47 & 20.83 \\
\hline & Dichloroacetate ${ }^{(c)}$ & -0.93 & 18.72 \\
\hline & Trifluoroacetate $\mathrm{e}^{(\mathrm{b}, \mathrm{c})}$ & 1.43 & 15.50 \\
\hline & Trichloroacetate ${ }^{(\mathrm{c})}$ & 0.94 & 16.17 \\
\hline & Heptafluorobutanoate ${ }^{(\mathrm{b}, \mathrm{c})}$ & 1.64 & 15.22 \\
\hline \multirow{10}{*}{ 80AN20W } & Acetate $^{(b)}$ & -5.05 & 24.35 \\
\hline & Formate & -3.10 & 21.68 \\
\hline & 2-Methylpropanoate & -5.55 & 25.02 \\
\hline & Fluoroacetate & -2.69 & 21.12 \\
\hline & Chloroacetate & -2.88 & 21.38 \\
\hline & Bromoacetate & -2.90 & 21.41 \\
\hline & Dichloroacetate ${ }^{(c)}$ & -1.09 & 18.93 \\
\hline & Trifluoroacetate ${ }^{(c)}$ & 1.34 & 15.62 \\
\hline & Trichloroacetate ${ }^{(c)}$ & 0.72 & 16.47 \\
\hline & Heptafluorobutanoate ${ }^{(\mathrm{c})}$ & 1.73 & 15.09 \\
\hline \multirow{11}{*}{$60 \mathrm{AN} 40 \mathrm{~W}$} & Acetate $^{(b, c)}$ & -4.51 & 23.61 \\
\hline & Formate & -2.45 & 20.79 \\
\hline & 2-Methylpropanoate & -4.97 & 24.23 \\
\hline & 2,2-Dimethylpropanoate & -5.43 & 24.86 \\
\hline & Fluoroacetate & -2.14 & 20.38 \\
\hline & Chloroacetate & -2.37 & 20.68 \\
\hline & Bromoacetate & -2.38 & 20.70 \\
\hline & Dichloroacetate ${ }^{(c)}$ & -0.74 & 18.46 \\
\hline & Trifluoroacetate ${ }^{(c)}$ & 1.63 & 15.22 \\
\hline & Trichloroacetate ${ }^{(c)}$ & 1.33 & 15.64 \\
\hline & Heptafluorobutanoate ${ }^{(\mathrm{c})}$ & 1.92 & 14.83 \\
\hline
\end{tabular}

(a) Binary solvents are expressed as volume fractions at $25^{\circ} \mathrm{C}$ : $\mathrm{A}=$ acetone, $\mathrm{AN}=$ acetonitrile, $\mathrm{W}=$ water.

(b) Data were taken from the reference: N. Streidl, B. Denegri, O. Kronja, and H. Mayr, Acc. Chem. Res. 43 (2010) 1537-1549.

(c) $\log k$ was calculated using the equation $\log k\left(25^{\circ} \mathrm{C}\right)=s_{\mathrm{f}}\left(E_{\mathrm{f}}+N_{\mathrm{f}}\right)$ and appropriate nucleofugality parameters. $E_{\mathrm{f}}$ value for the dianisylmethyl electrofuge is 0.00 . 